\title{
Model Rangkaian-T Pembangkit Listrik Tenaga Bayu untuk Analisis Aliran Daya Tiga-Fase
}

\section{(T-Circuit Model of Wind Power Plant for Three-Phase Power Flow Analysis)}

\author{
Rudy Gianto ${ }^{1}$
}

\begin{abstract}
Recently, penetration of wind power plant in electric power distribution system has increased significantly. The wind power plant penetration can affect the system's steady state and dynamic conditions. Furthermore, as the electric power distribution system is usually unbalanced, it has to be analyzed in a three-phase manner. Therefore, in order for the system conditions to be properly evaluated, development of a threephase model of the system components (including wind power plant) is necessary. This paper proposes a simple method for modeling and integrating fixed-speed wind power plant for steady state analysis (i.e., power flow analysis) of the three-phase distribution system. The proposed method is based on the $T$ circuit model which has previously been successfully applied to single-phase electric power systems. In this study, the singlephase T-circuit model is modified and extended so as to facilitate three-phase power flow analysis under unbalanced system conditions. Application of the proposed model in two three-phase distribution systems (i.e. 33-node and 25-node systems) is also investigated and presented in this paper. Results of the investigation show that the proposed method is valid and accurate.
\end{abstract}

Intisari-Akhir-akhir ini, penetrasi Pembangkit Listrik Tenaga Bayu (PLTB) pada sistem distribusi tenaga listrik mengalami peningkatan yang cukup signifikan. Penetrasi PLTB ini dapat memengaruhi kondisi keadaan mantap dan dinamik sistem tersebut. Lebih lanjut, sistem distribusi tenaga listrik biasanya tidak seimbang, sehingga harus dianalisis secara tigafase. Oleh karena itu, agar kondisi-kondisi sistem dapat dievaluasi dengan baik, pembentukan model tiga-fase dari komponen-komponen sistem (termasuk PLTB) merupakan hal yang sangat penting. Makalah ini mengusulkan metode sederhana dalam memodelkan dan mengintegrasikan PLTB kecepatan tetap untuk analisis keadaan mantap (atau analisis aliran daya) sistem distribusi tiga-fase. Metode yang diusulkan tersebut didasarkan pada model rangkaian-T yang sebelumnya telah berhasil diaplikasikan pada sistem fase-tunggal. Pada makalah ini, model rangkaian-T fase-tunggal tersebut dimodifikasi dan diperluas sehingga dapat memfasilitasi analisis aliran daya tiga-fase pada kondisi sistem tak-seimbang. Aplikasi usulan model pada dua sistem distribusi tiga-fase, yaitu sistem 33-simpul dan 25 simpul, juga diselidiki dan disajikan pada makalah ini. Hasil-hasil penyelidikan yang dilakukan pada sistem tersebut memperlihatkan bahwa metode yang diusulkan valid dan akurat.

Kata Kunci-Pembangkit Listrik Tenaga Bayu, Analisis Aliran Daya, Sistem Distribusi Tiga-Fase, Model Rangkaian-T.

${ }^{1}$ Jurusan Teknik Elektro, Fakultas Teknik, Universitas Tanjungpura, Jln. Prof. Dr. H. Hadari Nawawi, Pontianak, INDONESIA (e-mail: rudygianto@gmail.com)

\section{Pendahuluan}

Secara umum, sistem distribusi tenaga listrik sangat tidak seimbang [1]. Ketidakseimbangan ini dapat terjadi karena beban pada setiap fase tidak sama dan saluran-saluran distribusi yang tidak ditransposisi. Oleh karena itu, untuk sistem-sistem tersebut, teknik fase-tunggal tidak dapat lagi diaplikasikan dan teknik tiga-fase harus digunakan untuk menganalisisnya. Lebih lanjut, akhir-akhir ini, integrasi dari pembangkit-pembangkit tersebar (distributed generations) pada sistem distribusi juga mengalami peningkatan yang cukup signifikan.

Pembangkit-pembangkit tersebar biasanya berukuran kecil dan tersebar pada sistem distribusi. Sumber-sumber energi utama untuk pembangkit tersebar dengan energi terbarukan adalah angin, matahari, dan air. Namun, di antara ketiga sumber energi tersebut, sistem Pembangkit Listrik Tenaga Bayu (PLTB) lebih populer dan memiliki perkembangan teknologi yang lebih pesat [1].

Beberapa tahun terakhir ini, telah cukup banyak penelitian yang dilakukan dalam hal pemodelan dan integrasi PLTB pada analisis aliran daya sistem tenaga listrik. Sebagai contoh, telah mengusulkan metode-metode yang cukup menarik dalam mengintegrasikan PLTB kecepatan tetap pada analisis aliran daya [2]-[11]. Rangkaian ekuivalen generator induksi dari PLTB dikonversi menjadi model tiga-simpul, kemudian model tersebut diikutsertakan dalam analisis aliran daya [2] [4]. Aplikasi dari model tiga-simpul ini akan mengubah analisis aliran daya karena adanya penambahan dua cabang dan dua simpul PQ pada sistem tenaga listrik tempat PLTB tersebut terhubung. Dengan metode ini, program aliran daya standar dapat digunakan untuk menyelesaikan masalah aliran dayanya dan modifikasi terhadap kode program tidak perlu dilakukan.

Model-model matematik dari PLTB juga telah dikembangkan [5]-[11]. Persamaan-persamaan matematik ini kemudian, bersama-sama dengan persamaan aliran daya yang telah ada, diselesaikan secara iteratif. Referensi [5]-[7] mengusulkan model PLTB yang dibentuk dari persamaan yang diperoleh dari rangkaian ekuivalen- $\Pi$ atau $D$ generator induksi PLTB. Referensi [8] mengusulkan suatu metode yang didasarkan pada teori jaringan dua-terminal. Sementara itu, telah diusulkan juga suatu model yang diperoleh berdasarkan rangkaian ekuivalen $\mathrm{Y}$ atau $\mathrm{T}$ dari generator induksi PLTB [9]-[11]. Model tersebut diturunkan hanya dengan menggunakan hukum-hukum Kirchhoff dan Ohm.

Model-model PLTB yang diusulkan mengasumsikan sistem adalah seimbang, sehingga teknik aliran daya fase-tunggal 
dapat digunakan untuk menganalisisnya [2]-[11]. Namun, seperti yang telah diuraikan sebelumnya, sistem distribusi tenaga listrik umumnya sangat tidak seimbang dan harus dianalisis menggunakan teknik aliran daya tiga-fase. Dengan melihat latar belakang tersebut, makalah ini mengusulkan model PLTB tiga-fase yang dapat digunakan pada sistemsistem tak seimbang. Metode yang diusulkan ini didasarkan pada model rangkaian-T [9]. Pada makalah ini, modifikasi dan ekstensi terhadap model rangkaian-T [9] dilakukan, sehingga dapat memfasilitasi analisis aliran daya tiga-fase pada kondisikondisi sistem tak-seimbang. Perlu dicatat bahwa model pada [9] adalah lebih sederhana dibandingkan model pada [5]-[7] karena metode yang diusulkan pada [9] tidak memerlukan konversi dari rangkaian $\mathrm{Y}$ ke rangkaian D. Lebih lanjut, model pada [9] hanya membutuhkan satu set persamaan untuk merepresentasikan PLTB sehingga modifikasi dan ekstensinya pada sistem tiga-fase menjadi lebih mudah.

\section{ANALISIS AliRAn DAYA Sistem Distribusi TigA-FASE}

Masalah aliran daya biasanya diselesaikan menggunakan metode simpul dengan matriks admitans sering dipakai dalam analisisnya. Dalam bentuk besaran-besaran simpul, perilaku sistem distribusi tiga-fase dapat dijelaskan melalui (1).

$$
\boldsymbol{I}^{a b c}-\boldsymbol{Y}^{a b c} \boldsymbol{V}^{a b c}=\mathbf{0}
$$

dengan

$$
\begin{aligned}
& \boldsymbol{I}^{a b c}=\text { vektor dari arus-arus simpul } \\
& \boldsymbol{V}^{a b c}=\text { vektor dari tegangan-tegangan simpul } \\
& \boldsymbol{Y}^{a b c}=\text { matriks admitans sistem. }
\end{aligned}
$$

Untuk sistem distribusi yang memiliki $n$ buah simpul, $\boldsymbol{I}^{a b c}$, $\boldsymbol{V}^{a b c}$, dan $\boldsymbol{Y}^{a b c}$ akan memiliki bentuk-bentuk sebagai berikut:

$$
\begin{gathered}
\boldsymbol{I}^{a b c}=\left[\begin{array}{c}
\boldsymbol{I}_{1}^{a b c} \\
\boldsymbol{I}_{2}^{a b c} \\
\mathrm{M} \\
\boldsymbol{I}_{n}^{a b c}
\end{array}\right] ; \boldsymbol{V}^{a b c}=\left[\begin{array}{c}
\boldsymbol{V}_{1}^{a b c} \\
\boldsymbol{V}_{2}^{a b c} \\
\mathrm{M} \\
\boldsymbol{V}_{n}^{a b c}
\end{array}\right] \\
\boldsymbol{Y}^{a b c}=\left[\begin{array}{cccc}
\boldsymbol{Y}_{11}^{a b c} & \boldsymbol{Y}_{12}^{a b c} & \Lambda & \boldsymbol{Y}_{1 n}^{a b c} \\
\boldsymbol{Y}_{21}^{a b c} & \boldsymbol{Y}_{22}^{a b c} & \Lambda & \boldsymbol{Y}_{2 n}^{a b c} \\
\mathrm{M} & \mathrm{M} & \mathrm{O} & \mathrm{M} \\
\boldsymbol{Y}_{n 1}^{a b c} & \boldsymbol{Y}_{n 2}^{a b c} & \Lambda & \boldsymbol{Y}_{n n}^{a b c}
\end{array}\right]
\end{gathered}
$$

dengan

$$
\begin{gathered}
\boldsymbol{I}_{i}^{a b c}=\left[\begin{array}{c}
I_{i}^{a} \\
I_{i}^{b} \\
I_{i}^{c}
\end{array}\right] ; \boldsymbol{V}_{i}^{a b c}=\left[\begin{array}{c}
V_{i}^{a} \\
V_{i}^{b} \\
V_{i}^{c}
\end{array}\right] \\
\boldsymbol{Y}_{i i}^{a b c}=\left[\begin{array}{ccc}
Y_{i i}^{a a} & Y_{i i}^{a b} & Y_{i i}^{a c} \\
Y_{i i}^{b a} & Y_{i i}^{b b} & Y_{i i}^{b c} \\
Y_{i i}^{c a} & Y_{i i}^{c b} & Y_{i i}^{c c}
\end{array}\right]
\end{gathered}
$$

$$
\boldsymbol{Y}_{i j}^{a b c}=\left[\begin{array}{lll}
Y_{i j}^{a a} & Y_{i j}^{a b} & Y_{i j}^{a c} \\
Y_{i j}^{b a} & Y_{i j}^{b b} & Y_{i j}^{b c} \\
Y_{i j}^{c a} & Y_{i j}^{c b} & Y_{i j}^{c c}
\end{array}\right] .
$$

Vektor arus simpul pada (1) dapat juga dinyatakan dalam bentuk tegangan dan daya simpul seperti berikut.

$$
\boldsymbol{I}^{a b c}=\left\{\left[\operatorname{diag}\left(\boldsymbol{V}^{a b c}\right)\right]^{-1}\left(\boldsymbol{S}_{G}^{a b c}-\boldsymbol{S}_{L}^{a b c}\right)\right\}^{*}
$$

dengan

$$
\begin{aligned}
S_{G}^{a b c}= & \text { vektor dari daya-daya yang menuju simpul atau } \\
& \text { daya yang dibangkitkan } \\
S_{L}^{a b c}= & \text { vektor dari daya-daya yang meninggalkan simpul } \\
& \text { atau daya beban. }
\end{aligned}
$$

Untuk sistem distribusi yang memiliki $n$ buah simpul, formulasi untuk $\boldsymbol{S}_{\boldsymbol{G}}{ }^{a b c}$ dan $\boldsymbol{S}_{\boldsymbol{L}}{ }^{a b c}$ diberikan oleh

$$
S_{G}^{a b c}=\left[\begin{array}{c}
\boldsymbol{S}_{G 1}^{a b c} \\
\boldsymbol{S}_{G 2}^{a b c} \\
\mathrm{M} \\
\boldsymbol{S}_{G n}^{a b c}
\end{array}\right] ; \boldsymbol{S}_{L}^{a b c}=\left[\begin{array}{c}
\boldsymbol{S}_{L 1}^{a b c} \\
\boldsymbol{S}_{L 2}^{a b c} \\
\mathrm{M} \\
\boldsymbol{S}_{L n}^{a b c}
\end{array}\right]
$$

dengan

$$
S_{G i}^{a b c}=\left[\begin{array}{c}
S_{G i}^{a} \\
S_{G i}^{b} \\
S_{G i}^{c}
\end{array}\right] ; S_{L i}^{a b c}=\left[\begin{array}{c}
S_{L i}^{a} \\
S_{L i}^{b} \\
S_{L i}^{c}
\end{array}\right]
$$

Substitusi (4) pada (1) menghasilkan

$$
\left\{\left[\operatorname{diag}\left(\boldsymbol{V}^{a b c}\right)\right]^{-1}\left(\boldsymbol{S}_{G}^{a b c}-\boldsymbol{S}_{L}^{a b c}\right)\right\}^{*}-\boldsymbol{Y}^{a b c} \boldsymbol{V}^{a b c}=\mathbf{0}
$$

Persamaan (7) merupakan formulasi dari masalah aliran daya sistem distribusi tiga-fase. Semua besaran, baik yang diketahui (yang ditentukan) maupun yang tidak diketahui (yang akan dihitung), diperlihatkan pada Tabel I. Terlihat bahwa (7) adalah sekumpulan persamaan-persamaan nonlinier. Dalam analisis aliran daya, persamaan-persamaan ini harus diselesaikan secara simultan. Selanjutnya, hasil-hasil dari analisis aliran daya ini dapat digunakan untuk mengevaluasi kondisi-kondisi keadaan mantap dari sistem distribusi tersebut.

\section{MODEL RANGKAIAN-T DARI PLTB}

\section{A. Konfigurasi Dasar PLTB}

Dilihat dari kecepatan putarannya, PLTB dapat dibagi ke dalam dua kelompok, yaitu PLTB kecepatan tetap atau hampir tetap dan PLTB kecepatan variabel. Gbr. 1 memperlihatkan PLTB kecepatan tetap yang menggunakan Generator Induksi Rotor Sangkar (GIRS) sebagai konverter energi listrik utamanya [2]-[11]. PLTB tersebut diasumsikan terhubung 
TABEL I

BESARAN-BESARAN DALAM Formulasi MASAlah AliRAN DAYA SiSTEM DISTRIBUSI TIGA-FASE

\begin{tabular}{|c|c|c|}
\hline Simpul & Besaran yang Diketahui & Besaran yang Dicari \\
\hline GI & $\boldsymbol{Y}^{a b c} ; \boldsymbol{S}_{L i}^{a b c}$ & \\
& $\boldsymbol{V}_{i}^{a b c}=\left[\begin{array}{c}1 \angle 0^{o} \\
1 \angle-120^{o} \\
1 \angle 120^{o}\end{array}\right]$ & $\boldsymbol{S}_{G}^{a b c}$ \\
\hline Beban & $\boldsymbol{Y}^{a b c} ; \boldsymbol{S}_{L i}^{a b c}$ & \\
& $\boldsymbol{S}_{G}^{a b c}=\left[\begin{array}{lll}O & 0 & 0\end{array}\right]^{T}$ & $\boldsymbol{V}_{i}^{a b c}$ \\
\hline
\end{tabular}

GI = Gardu Induk

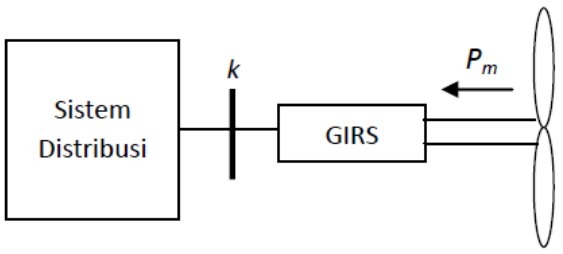

(a)

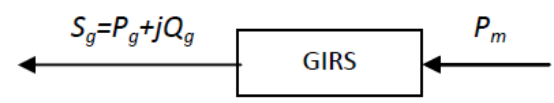

(b)

Gbr. 1 PLTB terhubung pada bus- $k$ sistem distribusi.

pada simpul $k$ suatu sistem distribusi. Pada Gbr. $1, P_{m}$ adalah masukan daya mekanik turbin dan $S_{g}$ adalah keluaran daya listrik PLTB. Gbr. 2 memperlihatkan rangkaian ekuivalen per fase generator induksi PLTB.

Besaran-besaran $R_{s}, X_{s}, R_{r}, X_{r}, R_{c}, X_{m}, R_{r}(1-s) / s$, dan $s$ pada Gbr. 2(a) berturut-turut menyatakan resistans rangkaian stator, reaktans rangkaian stator, resistans rangkaian rotor, reaktans rangkaian rotor, resistans rangkaian inti magnetik, reaktans rangkaian inti magnetik, resistans dinamik, dan slip generator. Lebih lanjut, besaran-besaran $V_{s}, I_{s}, V_{r}, I_{r}$, and $I_{m}$ pada Gbr. 2(b) digunakan untuk menyatakan tegangan stator, arus stator, tegangan rotor, arus rotor, dan arus inti magnetik. Impedansimpedansi $Z_{s}, Z_{r}$, and $Z_{m}$ pada gambar tersebut dapat dihitung melalui persamaan-persamaan berikut.

$$
\begin{gathered}
Z_{s}=R_{s}+j X_{s} \\
Z_{r}=R_{r}+j X_{r} \\
Z_{m}=j R_{c} X_{m} /\left(R_{c}+j X_{m}\right) .
\end{gathered}
$$

Perlu dicatat bahwa pada Gbr. 2(a), daya mekanik turbin $\left(P_{m}\right)$ dinyatakan sebagai daya aktif yang diserap oleh resistans dinamik $\left(R_{r}(1-s) / s\right)$, atau

$$
P_{m}=-R_{R} \frac{1-s}{s} I_{R} I_{R}^{*}
$$

Oleh karena itu, sumber daya konstan ekuivalen dapat digunakan untuk menyatakan resistans dinamik tersebut,

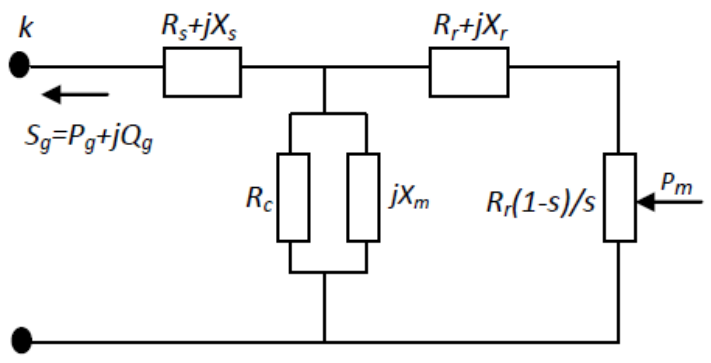

(a)

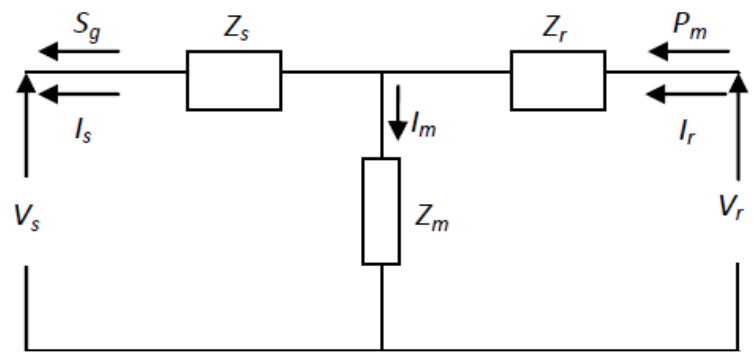

(b)

Gbr. 2. Rangkaian ekuivalen per fase GIRS.

seperti yang diperlihatkan pada Gbr. 2(b). Dengan demikian, (9) dapat dieliminasi dari persamaan aliran daya dan slip $s$ dapat dikeluarkan dari perhitungan aliran daya. Perlu dicatat bahwa pabrik pembuat turbin angin biasanya menyediakan kurva daya mekanik turbin, sehingga untuk setiap kecepatan angin, besar daya mekanik turbin tersebut dapat ditentukan atau diketahui nilainya.

\section{B. Model Rangkaian-T dari PLTB}

Berdasarkan Gbr. 2, keluaran daya listrik PLTB adalah

$$
S_{g}=P_{g}+j Q_{g}=V_{s} I_{s}^{*}
$$

dan masukan daya mekanik turbin adalah

$$
P_{m}=V_{r} I_{r}^{*}
$$

Lebih lanjut, dari Gbr. 2, tegangan rangkaian rotor dirumuskan sebagai

$$
V_{r}=V_{s}+I_{s} Z_{s}+I_{r} Z_{r}
$$

sedangkan arus rangkaian rotor adalah

$$
I_{r}=I_{s}+I_{m}
$$

dan arus rangkaian magnetik adalah

$$
I_{m}=\frac{V_{s}+I_{s} Z_{s}}{Z_{m}} .
$$

Substitusi (14) pada (13) menghasilkan arus rangkaian rotor sebagai

$$
I_{r}=V_{s} \frac{1}{Z_{m}}+I_{s} \frac{Z_{s}+Z_{m}}{Z_{m}} .
$$


Dengan menggunakan (15) pada (12), tegangan rangkaian rotor menjadi

$$
V_{r}=V_{s}\left(1+\frac{Z_{r}}{Z_{m}}\right)+I_{s}\left(Z_{s}+Z_{r}+\frac{Z_{s} Z_{r}}{Z_{m}}\right) .
$$

Substitusi (16) dan (15) pada (11) dan mengaturnya kembali menghasilkan

$$
\begin{aligned}
P_{m}= & \left(\frac{1}{Z_{m}^{*}}+\frac{Z_{r}}{Z_{m} Z_{m}^{*}}\right) V_{s} V_{s}^{*}+\left(1+\frac{Z_{s}^{*}}{Z_{m}^{*}}+\frac{Z_{r}}{Z_{m}}+\frac{Z_{s}^{*} Z_{r}}{Z_{m} Z_{m}^{*}}\right) V_{s} I_{s}^{*} \\
& +\left(\frac{Z_{s}}{Z_{m}^{*}}+\frac{Z_{s} Z_{r}}{Z_{m} Z_{m}^{*}}+\frac{Z_{r}}{Z_{m}^{*}}\right) V_{s}^{*} I_{s} \\
& +\left(Z_{s}+Z_{r}+\frac{Z_{s} Z_{s}^{*}}{Z_{m}^{*}}+\frac{Z_{s} Z_{r}}{Z_{m}}+\frac{Z_{s} Z_{s}^{*} Z_{r}}{Z_{m} Z_{m}^{*}}+\frac{Z_{s}^{*} Z_{r}}{Z_{m}^{*}}\right) I_{s} I_{s}^{*} .
\end{aligned}
$$

Dengan menggunakan (10) pada (17), rumusan daya mekanik turbin menjadi

$$
P_{m}=Z_{T 1} V_{v}+Z_{T 2} S_{g}+Z_{T 3} S_{g}^{*}+Z_{T 4} S_{v}
$$

dengan

$$
\begin{gathered}
V_{v}=V_{s} V_{s}^{*} \\
S_{v}=\frac{S_{g} S_{g}^{*}}{V_{s} V_{s}^{*}} \\
Z_{T 1}=\frac{1}{Z_{m}^{*}}+\frac{Z_{r}}{Z_{m} Z_{m}^{*}} \\
Z_{T 2}=1+\frac{Z_{s}^{*}}{Z_{m}^{*}}+\frac{Z_{r}}{Z_{m}}+\frac{Z_{s}^{*} Z_{r}}{Z_{m} Z_{m}^{*}} \\
Z_{T 3}=\frac{Z_{s}}{Z_{m}^{*}}+\frac{Z_{s} Z_{r}}{Z_{m} Z_{m}^{*}}+\frac{Z_{r}}{Z_{m}^{*}} \\
Z_{T 4}=Z_{s}+Z_{r}+\frac{Z_{s} Z_{s}^{*}}{Z_{m}^{*}}+\frac{Z_{s} Z_{r}}{Z_{m}}+\frac{Z_{s} Z_{s}^{*} Z_{r}}{Z_{m} Z_{m}^{*}}+\frac{Z_{s}^{*} Z_{r}}{Z_{m}^{*}} .
\end{gathered}
$$

Persamaan (10) merupakan model rangkaian-T fase-tunggal dari PLTB kecepatan tetap. Integrasi model ini pada analisis aliran daya suatu sistem distribusi tenaga listrik dapat dilihat secara lebih detail penelitian sebelumnya [9]. Berikut adalah uraian tentang modifikasi dan ekstensi model tersebut sehingga dapat digunakan untuk analisis aliran daya tiga-fase.

\section{MODEl RANGKAIAN-T UNTUK ALIRAN DAYA TIGA-FASE}

Untuk sistem tiga-fase, (18) dapat dimodifikasi menjadi sebagai berikut.

$\boldsymbol{P}_{m}^{a b c}=\boldsymbol{Z}_{T 1}^{a b c} \boldsymbol{V}_{v}^{a b c}+\boldsymbol{Z}_{T 2}^{a b c} \boldsymbol{S}_{g}^{a b c}+\boldsymbol{Z}_{T 3}^{a b c}\left(\boldsymbol{S}_{g}^{a b c}\right)^{*}+\boldsymbol{Z}_{T 4}^{a b c} \boldsymbol{S}_{v}^{a b c}$ dengan

$$
\begin{gathered}
\boldsymbol{P}_{m}^{a b c}=\left[\begin{array}{c}
P_{m} / 3 \\
P_{m} / 3 \\
P_{m} / 3
\end{array}\right] ; S_{g}^{a b c}=\left[\begin{array}{c}
S_{g}^{a} \\
S_{g}^{b} \\
S_{g}^{c}
\end{array}\right] \\
\boldsymbol{V}_{v}^{a b c}=\left[\begin{array}{c}
V_{s}^{a}\left(V_{s}^{a}\right)^{*} \\
V_{s}^{b}\left(V_{s}^{b}\right)^{*} \\
V_{s}^{b}\left(V_{s}^{b}\right)^{*}
\end{array}\right] ; S_{v}^{a b c}=\left[\begin{array}{l}
S_{g}^{a}\left(S_{g}^{a}\right)^{*} / V_{s}^{a}\left(V_{s}^{a}\right)^{*} \\
S_{g}^{b}\left(S_{g}^{b}\right)^{*} / V_{s}^{b}\left(V_{s}^{b}\right)^{*} \\
S_{g}^{c}\left(S_{g}^{c}\right)^{*} / V_{s}^{c}\left(V_{s}^{c}\right)^{*}
\end{array}\right] \\
\boldsymbol{Z}_{T i}^{a b c}=\left[\begin{array}{ccc}
Z_{T i}^{a} & 0 & 0 \\
0 & Z_{T i}^{b} & 0 \\
0 & 0 & Z_{T i}^{c}
\end{array}\right] ; i=1,2,3,4
\end{gathered}
$$

Elemen-elemen diagonal utama dari matriks $\boldsymbol{Z}_{T i}^{a b c}$ pada (21c) akan memiliki formulasi sebagai berikut.

$$
\begin{gathered}
Z_{T 1}^{p}=\frac{1}{\left(Z_{m}^{p}\right)^{*}}+\frac{Z_{r}^{p}}{Z_{m}^{p}\left(Z_{m}^{p}\right)^{*}} \\
Z_{T 2}^{p}=1+\frac{\left(Z_{s}^{p}\right)^{*}}{\left(Z_{m}^{p}\right)^{*}}+\frac{Z_{r}^{p}}{Z_{m}^{p}}+\frac{\left(Z_{s}^{p}\right)^{*} Z_{r}^{p}}{Z_{m}^{p}\left(Z_{m}^{p}\right)^{*}} \\
Z_{T 3}^{p}=\frac{Z_{s}^{p}}{\left(Z_{m}^{p}\right)^{*}}+\frac{Z_{s}^{p} Z_{r}^{p}}{Z_{m}^{p}\left(Z_{m}^{p}\right)^{*}}+\frac{Z_{r}^{p}}{\left(Z_{m}^{p}\right)^{*}} \\
Z_{T 4}^{p}=Z_{s}^{p}+Z_{r}^{p}+\frac{Z_{s}^{p}\left(Z_{s}^{p}\right)^{*}}{\left(Z_{m}^{p}\right)^{*}}+\frac{Z_{s}^{p} Z_{r}^{p}}{Z_{m}^{p}}+\frac{Z_{s}^{p}\left(Z_{s}^{p}\right)^{*} Z_{r}^{p}}{Z_{m}^{p}\left(Z_{m}^{p}\right)^{*}}+\frac{\left(Z_{s}^{p}\right)^{*} Z_{r}^{p}}{\left(Z_{m}^{p}\right)^{*}}
\end{gathered}
$$

dengan $p=a, b, c$; sedangkan impedans-impedans $Z_{s}^{p}, Z_{r}^{p}$, dan $Z_{m}^{p}$ dihitung menggunakan (23).

$$
\begin{aligned}
& Z_{S}^{p}=R_{s}^{p}+j X_{s}^{p} \\
& Z_{r}^{p}=R_{r}^{p}+j X_{r}^{p} \\
& Z_{m}^{p}=j R_{c}^{p} X_{m}^{p} /\left(R_{c}^{p}+j X_{m}^{p}\right) .
\end{aligned}
$$

Untuk melakukan analisis aliran daya tiga-fase dari sistem yang mengandung PLTB, pertama-tama, (20) diatur atau ditulis kembali seperti (24).

$$
\boldsymbol{P}_{m}^{a b c}-\boldsymbol{Z}_{T 1}^{a b c} \boldsymbol{V}_{v}^{a b c}-\boldsymbol{Z}_{T 2}^{a b c} \boldsymbol{S}_{g}^{a b c}-\boldsymbol{Z}_{T 3}^{a b c}\left(\boldsymbol{S}_{g}^{a b c}\right)^{*}-\boldsymbol{Z}_{T 4}^{a b c} \boldsymbol{S}_{v}^{a b c}=\mathbf{0} .
$$

Kemudian, untuk simpul-simpul yang mengandung PLTB, (24) digabungkan dengan (7). Gabungan persamaan ini, bersama-sama dengan persamaan-persamaan simpul lainnya, diselesaikan secara simultan. Tabel II memperlihatkan seluruh besaran dan persamaan dalam formulasi masalah aliran daya tiga-fase untuk sistem distribusi tenaga listrik yang 
TABEL II

BESARAN-BESARAN DALAM FormUlasi MASAlah ALIRAN DAYA SiSTEM DISTRIBUSI TIGA-FASE YANG MENGANDUNG PLTB

\begin{tabular}{|c|c|c|c|}
\hline Simpul & Pers. & Besaran yang Ditentukan & $\begin{array}{c}\text { Besaran yang } \\
\text { Dicari }\end{array}$ \\
\hline GI & (7) & $\begin{array}{c}\boldsymbol{Y}^{a b c} ; \boldsymbol{S}_{L i}^{a b c} \\
\boldsymbol{V}_{i}^{a b c}=\left[\begin{array}{c}1 \angle 0^{o} \\
1 \angle-120^{o} \\
1 \angle 120^{\circ}\end{array}\right]\end{array}$ & $S_{G}^{a b c}$ \\
\hline Beban & (7) & $\begin{array}{c}\boldsymbol{Y}^{a b c} ; \boldsymbol{S}_{L i}^{a b c} \\
\boldsymbol{S}_{G}^{a b c}=\left[\begin{array}{lll}0 & 0 & 0\end{array}\right]^{T}\end{array}$ & $V_{i}^{a b c}$ \\
\hline PLTB & $\begin{array}{l}(7) \\
\text { dan } \\
(24)\end{array}$ & $\begin{array}{c}\boldsymbol{Y}^{a b c} ; \boldsymbol{S}_{L i}^{a b c} \\
Z_{S}^{p} ; Z_{r}^{p} ; Z_{m}^{p} ; p=a, b, c\end{array}$ & $\begin{array}{l}V_{i}^{a b c} \\
S_{g}^{a b c}\end{array}$ \\
\hline
\end{tabular}

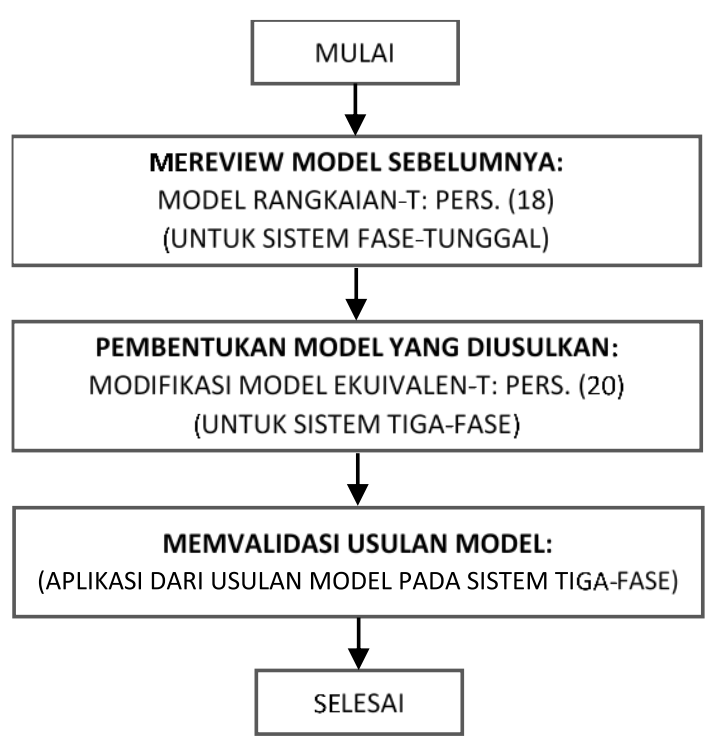

Gbr. 3 Diagram alir penelitian.

mengandung PLTB. Perlu dicatat bahwa pada formulasi tersebut, tegangan pada simpul PLTB atau tegangan terminal PLTB juga merupakan tegangan stator dari generator induksi PLTB, serta injeksi daya pada simpul PLTB juga merupakan keluaran daya PLTB, sehingga

$$
\begin{aligned}
& \boldsymbol{V}_{j}^{a b c}=\boldsymbol{V}_{s}^{a b c} \\
& \boldsymbol{S}_{G j}^{a b c}=\boldsymbol{S}_{g}^{a b c}
\end{aligned}
$$

dengan $j$ adalah simpul tempat PLTB tersebut terhubung.

Persamaan (7) dan (24) merupakan formulasi lengkap masalah aliran daya dari sistem distribusi tiga-fase yang mengandung PLTB. Sesuai diagram alir pada Gbr. 3, langkah selanjutnya adalah melakukan validasi terhadap usulan model dengan cara menerapkannya pada sistem distribusi tiga-fase. Hal ini akan dibahas pada subbagian berikutnya.
TABEL III

\begin{tabular}{|c|c|c|c|c|c|c|}
\hline \multirow[b]{2}{*}{ Sal. } & \multirow[b]{2}{*}{$\begin{array}{l}\text { Simpul } \\
\text { Kirim }\end{array}$} & \multirow[b]{2}{*}{$\begin{array}{l}\text { Simpul } \\
\text { Terima }\end{array}$} & \multicolumn{2}{|c|}{ Impedans* } & \multicolumn{2}{|c|}{ Beban** } \\
\hline & & & $\begin{array}{c}R \\
\text { (ohm) }\end{array}$ & $\begin{array}{c}X \\
\text { (ohm) }\end{array}$ & $\begin{array}{c}P_{L} \\
(\mathbf{k W})\end{array}$ & $\underset{(\mathbf{k V A R})}{Q_{L}}$ \\
\hline 1 & 1 & 2 & 0,0922 & 0,0470 & 100 & 60 \\
\hline 2 & 2 & 3 & 0,4930 & 0,2511 & 90 & 40 \\
\hline 3 & 3 & 4 & 0,3660 & 0,1864 & 120 & 80 \\
\hline 4 & 4 & 5 & 0,3811 & 0,1941 & 60 & 30 \\
\hline 5 & 5 & 6 & 0,8190 & 0,7070 & 60 & 20 \\
\hline 6 & 6 & 7 & 0,1872 & 0,6188 & 200 & 100 \\
\hline 7 & 7 & 8 & 1,7114 & 1,2351 & 200 & 100 \\
\hline 8 & 8 & 9 & 1,0300 & 0,7400 & 60 & 20 \\
\hline 9 & 9 & 10 & 1,0440 & 0,7400 & 60 & 20 \\
\hline 10 & 10 & 11 & 0,1966 & 0,0650 & 45 & 30 \\
\hline 11 & 11 & 12 & 0,3744 & 0,1238 & 60 & 35 \\
\hline 12 & 12 & 13 & 1,4680 & 1,1550 & 60 & 35 \\
\hline 13 & 13 & 14 & 0,5416 & 0,7129 & 120 & 80 \\
\hline 14 & 14 & 15 & 0,5910 & 0,5260 & 60 & 10 \\
\hline 15 & 15 & 16 & 0,7463 & 0,5450 & 60 & 20 \\
\hline 16 & 16 & 17 & 1,2890 & 1,7210 & 60 & 20 \\
\hline 17 & 17 & 18 & 0,7320 & 0,5740 & 90 & 40 \\
\hline 18 & 2 & 19 & 0,1640 & 0,1565 & 90 & 40 \\
\hline 19 & 19 & 20 & 1,5042 & 1,3554 & 90 & 40 \\
\hline 20 & 20 & 21 & 0,4095 & 0,4784 & 90 & 40 \\
\hline 21 & 21 & 22 & 0,7089 & 0,9373 & 90 & 40 \\
\hline 22 & 3 & 23 & 0,4512 & 0,3083 & 90 & 50 \\
\hline 23 & 23 & 24 & 0,8980 & 0,7091 & 420 & 200 \\
\hline 24 & 24 & 25 & 0,8960 & 0,7011 & 420 & 200 \\
\hline 25 & 6 & 26 & 0,2030 & 0,1034 & 60 & 25 \\
\hline 26 & 26 & 27 & 0,2842 & 0,1447 & 60 & 25 \\
\hline 27 & 27 & 28 & 1,0590 & 0,9337 & 60 & 20 \\
\hline 28 & 28 & 29 & 0,8042 & 0,7006 & 120 & 70 \\
\hline 29 & 29 & 30 & 0,5075 & 0,2585 & 200 & 600 \\
\hline 30 & 30 & 31 & 0,9744 & 0,9630 & 150 & 70 \\
\hline 31 & 31 & 32 & 0,3105 & 0,3619 & 210 & 100 \\
\hline 32 & 32 & 33 & 0,3410 & 0,5302 & 60 & 40 \\
\hline
\end{tabular}

DATA SISTEM 33-SIMPUL

*Impedans: $Z^{a a}=Z^{b b}=Z^{c c}=R+j X ; Z^{a b}=Z^{b c}=Z^{b c}=0$

**Beban: $S_{L}^{a}=S_{L}^{b}=S_{L}^{c}=P_{L}+j Q_{L}$

**Beban terhubung pada simpul terima

\section{STUdi KasUS}

\section{A. Sistem Test}

Untuk memvalidasi metode yang diusulkan pada bagian IV, dua sistem distribusi berikut akan digunakan.

1) Sistem Distribusi 33-Simpul: Diagram garis tunggal dari sistem 33-simpul diperlihatkan pada Gbr. 4 [8], [9], [12]. Sistem ini adalah sistem seimbang $12,66 \mathrm{kV}$ dengan beban total tiga-fase sebesar $11.145 \mathrm{~kW}$ dan $6.900 \mathrm{kVAR}$ (per fase: $3.715 \mathrm{~kW}$ dan $2.300 \mathrm{kVAR}$ ). Data sistem disajikan pada Tabel III. Karena seimbang, sistem dapat dianalisis dengan menggunakan teknik fase-tunggal. Namun, pada makalah ini sistem dianalisis menggunakan teknik tiga-fase untuk keperluan proses validasi dari metode yang diusulkan pada bagian IV. PLTB dengan rating daya 3 MW diasumsikan terhubung pada simpul 33. Data dari generator induksi PLTB diperlihatkan pada Tabel IV.

2) Sistem Distribusi 25-Simpul: Diagram garis tunggal dari sistem 25-simpul diperlihatkan pada Gbr. 5 [13], [14]. Tidak 
TABEL IV

DATA GIRS PLTB SISTEM 33-SIMPUL

\begin{tabular}{|c|c|}
\hline Parameter & Nilai Resistansi/Reaktansi (ohm) \\
\hline \multirow{2}{*}{ Rangkaian stator } & $R_{s}{ }^{a}=R_{s}{ }^{b}=R_{s}{ }^{c}=1,602756$ \\
& $X_{s}{ }^{a}=X_{s}^{b}=X_{s}{ }^{c}=8,013780$ \\
\hline \multirow{2}{*}{ Rangkaian rotor } & $R_{r}{ }^{a}=R_{r}{ }^{b}=R_{r}{ }^{c}=1,602756$ \\
& $X_{r}{ }^{a}=X_{r}{ }^{b}=X_{r}{ }^{c}=8,013780$ \\
\hline \multirow{2}{*}{ Rangkaian inti magnetik } & $R_{c}{ }^{a}=R_{c}{ }^{b}=R_{c}{ }^{c}=16.027,560$ \\
& $X_{m}{ }^{a}=X_{m}{ }^{b}=X_{m}{ }^{c}=801,378$ \\
\hline
\end{tabular}

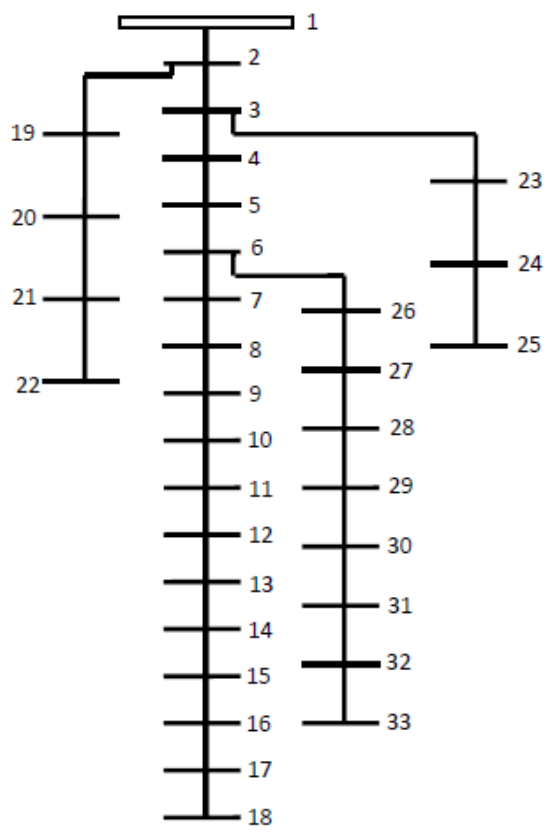

Gbr. 4 Sistem distribusi 33-simpul.

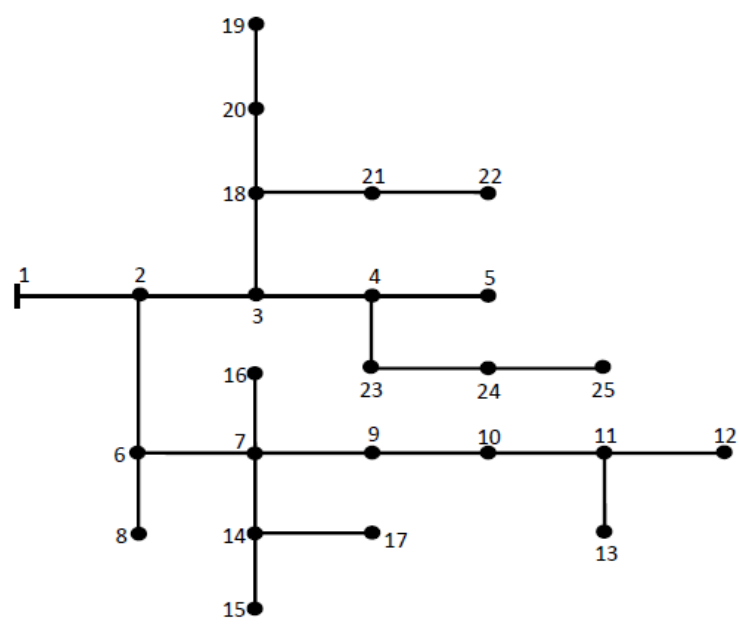

Gbr. 5 Sistem distribusi 25-simpul.

seperti sistem 33-simpul, sistem 25-simpul merupakan sistem tak-seimbang 4,16 kV dengan beban total tiga-fase sebesar 3.919,9 kW dan 2.884 kVAR (fase-a: 1.298,3 kW dan 957 kVAR; fase-b: $1.318,3 \mathrm{~kW}$ dan $967 \mathrm{kVAR}$; fase-c: $1.303,3$ kW dan $960 \mathrm{kVAR}$ ). Data sistem diberikan pada Tabel V sampai Tabel VII. PLTB dengan rating daya 3 MW diasumsikan terhubung pada simpul 25. Data dari generator induksi PLTB diperlihatkan pada Tabel VIII.
TABEL V

IMPEDANS SALURAN SISTEM 25-SIMPUL

\begin{tabular}{|c|c|c|c|c|}
\hline \multirow{2}{*}{$\begin{array}{c}\text { Tipe } \\
\text { Konduktor }\end{array}$} & \multicolumn{3}{|c|}{ Impedans (ohm/mil) } \\
\cline { 2 - 5 } & a & b & c \\
\hline \multirow{3}{*}{1} & $\mathrm{a}$ & $0,3686+\mathrm{j} 0,6852$ & $0,0169+\mathrm{j} 0,1515$ & $0,0155+\mathrm{j} 0,1098$ \\
\cline { 2 - 5 } & $\mathrm{b}$ & $0,0169+\mathrm{j} 0,1515$ & $0,3757+\mathrm{j} 0,6715$ & $0,0188+\mathrm{j} 0,2072$ \\
\cline { 2 - 5 } & $\mathrm{c}$ & $0,0155+\mathrm{j} 0,1098$ & $0,0188+\mathrm{j} 0,2072$ & $0,3723+\mathrm{j} 0,6783$ \\
\hline \multirow{3}{*}{2} & $\mathrm{a}$ & $0,9775+\mathrm{j} 0,8717$ & $0,0167+\mathrm{j} 0,1697$ & $0,0152+\mathrm{j} 0,1264$ \\
\cline { 2 - 5 } & $\mathrm{b}$ & $0,0167+\mathrm{j} 0,1697$ & $0,9844+\mathrm{j} 0,8654$ & $0,0186+\mathrm{j} 0,2275$ \\
\cline { 2 - 5 } & $\mathrm{c}$ & $0,0152+\mathrm{j} 0,1264$ & $0,0186+\mathrm{j} 0,2275$ & $0,9810+\mathrm{j} 0,8648$ \\
\hline \multirow{3}{*}{3} & $\mathrm{a}$ & $1,9280+\mathrm{j} 1,4194$ & $0,0161+\mathrm{j} 0,1183$ & $0,0161+\mathrm{j} 0,1183$ \\
\cline { 2 - 5 } & $\mathrm{b}$ & $0,0161+\mathrm{j} 0,1183$ & $1,9308+\mathrm{j} 1,4215$ & $0,0161+\mathrm{j} 0,1183$ \\
\cline { 2 - 5 } & $\mathrm{c}$ & $0,0161+\mathrm{j} 0,1183$ & $0,0161+\mathrm{j} 0,1183$ & $1,9337+\mathrm{j} 1,4236$ \\
\hline
\end{tabular}

TABEL VI

TIPE DAN PANJANG SALURAN SISTEM 25-SIMPUL

\begin{tabular}{|c|c|c|c|}
\hline No. & Saluran & $\begin{array}{c}\text { Tipe } \\
\text { Konduktor }\end{array}$ & Panjang (ft) \\
\hline 1 & $1-2$ & 1 & 1.000 \\
\hline 2 & $2-3$ & 1 & 500 \\
\hline 3 & $2-6$ & 2 & 500 \\
\hline 4 & $3-4$ & 1 & 500 \\
\hline 5 & $3-18$ & 2 & 500 \\
\hline 6 & $4-5$ & 2 & 500 \\
\hline 7 & $4-23$ & 2 & 400 \\
\hline 8 & $6-7$ & 2 & 500 \\
\hline 9 & $6-8$ & 2 & 1.000 \\
\hline 10 & $7-9$ & 2 & 500 \\
\hline 11 & $7-14$ & 2 & 500 \\
\hline 12 & $7-16$ & 2 & 500 \\
\hline 13 & $9-10$ & 2 & 500 \\
\hline 14 & $10-11$ & 2 & 300 \\
\hline 15 & $11-12$ & 3 & 200 \\
\hline 16 & $11-13$ & 3 & 200 \\
\hline 17 & $14-15$ & 2 & 300 \\
\hline 18 & $14-17$ & 3 & 300 \\
\hline 19 & $18-20$ & 2 & 500 \\
\hline 20 & $18-21$ & 3 & 400 \\
\hline 21 & $20-19$ & 3 & 400 \\
\hline 22 & $21-22$ & 3 & 400 \\
\hline 23 & $23-24$ & 2 & 400 \\
\hline 24 & $24-25$ & 3 & 400 \\
\hline
\end{tabular}

\section{B. Hasil dan Pembahasan}

Hasil-hasil dari analisis aliran daya untuk sistem distribusi 33-simpul diperlihatkan pada Tabel IX sampai Tabel XII. Karena sistem bersifat seimbang, besaran-besaran listrik (besar tegangan terminal serta keluaran daya PLTB dan GI) pada setiap fase adalah sama. Perlu dicatat bahwa hasil-hasil pada Tabel IX sampai Tabel XII tersebut sangat sesuai dengan hasil-hasil pada penelitian sebelumnya [8], [9]. Hal ini mengindikasikan bahwa metode yang diusulkan valid dan akurat.

Tabel XIII sampai Tabel XVI menyajikan hasil-hasil analisis aliran daya untuk sistem distribusi 25-simpul. Karena sistem tak-seimbang, terlihat bahwa besaran-besaran listrik pada ketiga fase tidak sama. Hasil-hasil analisis aliran daya tersebut juga menunjukkan bahwa dengan meningkatnya 
TABEL VII

DATA BEBAN SISTEM 25-SIMPUL

\begin{tabular}{|c|c|c|c|c|c|c|}
\hline \multirow{3}{*}{ Simpul } & \multicolumn{2}{|c|}{ Fase-a } & \multicolumn{2}{c|}{ Fase-b } & \multicolumn{2}{c|}{ Fase-c } \\
\cline { 2 - 7 } & $\begin{array}{c}\boldsymbol{P}_{\boldsymbol{L}} \\
(\mathbf{k W})\end{array}$ & $\begin{array}{c}\boldsymbol{Q}_{\boldsymbol{L}} \\
(\mathbf{k V A R})\end{array}$ & $\begin{array}{c}\boldsymbol{P}_{\boldsymbol{L}} \\
(\mathbf{k W})\end{array}$ & $\begin{array}{c}\boldsymbol{Q}_{\boldsymbol{L}} \\
(\mathbf{k V A R})\end{array}$ & $\begin{array}{c}\boldsymbol{P}_{\boldsymbol{L}} \\
(\mathbf{k W})\end{array}$ & $\begin{array}{c}\boldsymbol{Q}_{\boldsymbol{L}} \\
(\mathbf{k V A R})\end{array}$ \\
\hline 2 & 0 & 0 & 0 & 0 & 0 & 0 \\
\hline 3 & 35 & 25 & 40 & 30 & 45 & 32 \\
\hline 4 & 50 & 40 & 60 & 45 & 50 & 35 \\
\hline 5 & 40 & 30 & 40 & 30 & 40 & 30 \\
\hline 6 & 40 & 30 & 45 & 32 & 35 & 25 \\
\hline 7 & 0 & 0 & 0 & 0 & 0 & 0 \\
\hline 8 & 40 & 30 & 40 & 30 & 40 & 30 \\
\hline 9 & 60 & 45 & 50 & 40 & 50 & 35 \\
\hline 10 & 35 & 25 & 40 & 30 & 45 & 32 \\
\hline 11 & 45 & 32 & 35 & 25 & 40 & 30 \\
\hline 12 & 50 & 35 & 60 & 45 & 50 & 40 \\
\hline 13 & 35 & 25 & 45 & 32 & 40 & 30 \\
\hline 14 & 50 & 35 & 50 & 40 & 60 & 45 \\
\hline 15 & 133 & 100 & 133 & 100 & 133 & 100 \\
\hline 16 & 40 & 30 & 40 & 30 & 40 & 30 \\
\hline 17 & 40 & 30 & 35 & 25 & 45 & 32 \\
\hline 18 & 40 & 30 & 40 & 30 & 40 & 30 \\
\hline 19 & 60 & 45 & 50 & 35 & 50 & 40 \\
\hline 20 & 35 & 25 & 40 & 30 & 45 & 32 \\
\hline 21 & 40 & 30 & 35 & 25 & 45 & 32 \\
\hline 22 & 50 & 35 & 60 & 45 & 50 & 40 \\
\hline 23 & 120 & 90 & 100 & 80 & 100 & 70 \\
\hline 24 & 140 & 100 & 180 & 128 & 160 & 120 \\
\hline 25 & 120 & 90 & 100 & 60 & 100 & 70 \\
\hline
\end{tabular}

TABEL VIII

DATA GIRS PLTB SISTEM 25-SIMPUL

\begin{tabular}{|c|c|}
\hline Parameter & Nilai Resistans/Reaktans (ohm) \\
\hline \multirow{2}{*}{ Rangkaian stator } & $\mathrm{R}_{\mathrm{s}}{ }^{\mathrm{a}}=\mathrm{R}_{\mathrm{s}}{ }^{\mathrm{b}}=\mathrm{R}_{\mathrm{s}}{ }^{\mathrm{c}}=0,057685$ \\
& $\mathrm{X}_{\mathrm{s}}{ }^{\mathrm{a}}=\mathrm{X}_{\mathrm{s}}{ }^{\mathrm{b}}=\mathrm{X}_{\mathrm{s}}{ }^{\mathrm{c}}=0,288427$ \\
\hline \multirow{2}{*}{ Rangkaian rotor } & $\mathrm{R}_{\mathrm{r}}{ }^{\mathrm{a}}=\mathrm{R}_{\mathrm{r}}{ }^{\mathrm{b}}=\mathrm{R}_{\mathrm{r}}{ }^{\mathrm{c}}=0,057685$ \\
& $\mathrm{X}_{\mathrm{r}}{ }^{\mathrm{a}}=\mathrm{X}_{\mathrm{r}}{ }^{\mathrm{b}}=\mathrm{X}_{\mathrm{r}}{ }^{\mathrm{c}}=0,288427$ \\
\hline \multirow{2}{*}{ Rangkaian inti magnetik } & $\mathrm{R}_{\mathrm{c}}{ }^{\mathrm{a}}=\mathrm{R}_{\mathrm{c}}{ }^{\mathrm{b}}=\mathrm{R}_{\mathrm{c}}{ }^{\mathrm{c}}=576,85$ \\
& $\mathrm{X}_{\mathrm{m}}{ }^{\mathrm{a}}=\mathrm{X}_{\mathrm{m}}{ }^{\mathrm{b}}=\mathrm{X}_{\mathrm{m}}{ }^{\mathrm{c}}=28,84$ \\
\hline
\end{tabular}

TABEL IX

TEGANGAN TERMINAL PLTB SISTEM 33-SIMPUL

\begin{tabular}{|c|c|c|c|}
\hline $\begin{array}{c}\boldsymbol{P}_{\boldsymbol{m}} \\
(\mathbf{k W})\end{array}$ & $\begin{array}{c}\text { Fase-a } \\
(\mathbf{k V})\end{array}$ & $\begin{array}{c}\text { Fase-b } \\
(\mathbf{k V})\end{array}$ & $\begin{array}{c}\text { Fase-c } \\
(\mathbf{k V})\end{array}$ \\
\hline 300 & $11,57 \angle 1,03^{0}$ & $11,57 \angle-118,97^{0}$ & $11,57 \angle 121,03^{0}$ \\
\hline 600 & $11,63 \angle 1,26^{0}$ & $11,63 \angle-118,74^{0}$ & $11,63 \angle 121,26^{0}$ \\
\hline 900 & $11,68 \angle 1,48^{0}$ & $11,68 \angle-118,52^{0}$ & $11,68 \angle 121,48^{0}$ \\
\hline 1.200 & $11,74 \angle 1,72^{0}$ & $11,74 \angle-118,28^{0}$ & $11,74 \angle 121,72^{0}$ \\
\hline 1.500 & $11,79 \angle 1,95^{0}$ & $11,79 \angle-118,05^{0}$ & $11,79 \angle 121,95^{0}$ \\
\hline 1.800 & $11,84 \angle 2,19^{0}$ & $11,84 \angle-117,81^{0}$ & $11,84 \angle 122,19^{0}$ \\
\hline 2.100 & $11,88 \angle 2,43^{0}$ & $11,88 \angle-117,57^{0}$ & $11,88 \angle 122,43^{0}$ \\
\hline 2.400 & $11,93 \angle 2,67^{0}$ & $11,93 \angle-117,33^{0}$ & $11,93 \angle 122,67^{0}$ \\
\hline 2.700 & $11,97 \angle 2,91^{0}$ & $11,97 \angle-117,09^{0}$ & $11,97 \angle 122,91^{0}$ \\
\hline 3.000 & $12,01 \angle 3,16^{0}$ & $12,01 \angle-116,84^{0}$ & $12,01 \angle 123,16^{0}$ \\
\hline
\end{tabular}

masukan daya mekanik turbin, keluaran daya aktif PLTB ikut naik. Namun, nilai totalnya sedikit lebih kecil dibanding daya mekanik karena adanya rugi-rugi daya pada PLTB. Sementara itu, keluaran daya reaktif PLTB adalah negatif, yang artinya
TABEL $X$

KELUARAN DAYA PLTB SISTEM 33-SIMPUL

\begin{tabular}{|c|c|c|c|}
\hline $\begin{array}{c}\boldsymbol{P}_{\boldsymbol{m}} \\
(\mathbf{k W})\end{array}$ & $\begin{array}{c}\text { Fase-a } \\
(\mathbf{k W , ~ k V A R})\end{array}$ & $\begin{array}{c}\text { Fase-b } \\
(\mathbf{k W}, \mathbf{k V A R})\end{array}$ & $\begin{array}{c}\text { Fase-c } \\
(\mathbf{k W}, \mathbf{k V A R})\end{array}$ \\
\hline 300 & $91,24-\mathrm{j} 166,97$ & $91,24-\mathrm{j} 166,97$ & $91,24-\mathrm{j} 166,97$ \\
\hline 600 & $190,43-\mathrm{j} 172,45$ & $190,43-\mathrm{j} 172,45$ & $190,43-\mathrm{j} 172,45$ \\
\hline 900 & $289,17-\mathrm{j} 180,13$ & $289,17-\mathrm{j} 180,13$ & $289,17-\mathrm{j} 180,13$ \\
\hline 1.200 & $387,48-\mathrm{j} 189,94$ & $387,48-\mathrm{j} 189,94$ & $387,48-\mathrm{j} 189,94$ \\
\hline 1.500 & $485,36-\mathrm{j} 201,81$ & $485,36-\mathrm{j} 201,81$ & $485,36-\mathrm{j} 201,81$ \\
\hline 1.800 & $582,82-\mathrm{j} 215,70$ & $582,82-\mathrm{j} 215,70$ & $582,82-\mathrm{j} 215,70$ \\
\hline 2.100 & $679,88-\mathrm{j} 231,54$ & $679,88-\mathrm{j} 231,54$ & $679,88-\mathrm{j} 231,54$ \\
\hline 2.400 & $776,55-\mathrm{j} 249,29$ & $776,55-\mathrm{j} 249,29$ & $776,55-\mathrm{j} 249,29$ \\
\hline 2.700 & $872,83-\mathrm{j} 268,93$ & $872,83-\mathrm{j} 268,93$ & $872,83-\mathrm{j} 268,93$ \\
\hline 3.000 & $968,72-\mathrm{j} 290,42$ & $968,72-\mathrm{j} 290,42$ & $968,72-\mathrm{j} 290,42$ \\
\hline
\end{tabular}

TABEL XI

KelUARAN DAYA GI SISTEM 33-SIMPUL

\begin{tabular}{|c|c|c|c|}
\hline $\begin{array}{c}\boldsymbol{P}_{\boldsymbol{m}} \\
(\mathbf{k W})\end{array}$ & $\begin{array}{c}\text { Fase-a } \\
(\mathbf{k W}, \mathbf{k V A R})\end{array}$ & $\begin{array}{c}\text { Fase-b } \\
(\mathbf{k W}, \mathbf{k V A R})\end{array}$ & $\begin{array}{c}\text { Fase-c } \\
(\mathbf{k W , ~ k V A R})\end{array}$ \\
\hline 300 & $3.842,3+\mathrm{j} 2.613,5$ & $3.842,3+\mathrm{j} 2.613,5$ & $3.842,3+\mathrm{j} 2.613,5$ \\
\hline 600 & $3.732,6+\mathrm{j} 2.614,0$ & $3.732,6+\mathrm{j} 2.614,0$ & $3.732,6+\mathrm{j} 2.614,0$ \\
\hline 900 & $3.624,9+\mathrm{j} 2.615,8$ & $3.624,9+\mathrm{j} 2.615,8$ & $3.624,9+\mathrm{j} 2.615,8$ \\
\hline 1.200 & $3.519,0+\mathrm{j} 2.620,8$ & $3.519,0+\mathrm{j} 2.620,8$ & $3.519,0+\mathrm{j} 2.620,8$ \\
\hline 1.500 & $3.414,8+\mathrm{j} 2.628,9$ & $3.414,8+\mathrm{j} 2.628,9$ & $3.414,8+\mathrm{j} 2.628,9$ \\
\hline 1.800 & $3.312,4+\mathrm{j} 2.640,0$ & $3.312,4+\mathrm{j} 2.640,0$ & $3.312,4+\mathrm{j} 2.640,0$ \\
\hline 2.100 & $3.211,6+\mathrm{j} 2.654,0$ & $3.211,6+\mathrm{j} 2.654,0$ & $3.211,6+\mathrm{j} 2.654,0$ \\
\hline 2.400 & $3.112,5+\mathrm{j} 2.670,9$ & $3.112,5+\mathrm{j} 2.670,9$ & $3.112,5+\mathrm{j} 2.670,9$ \\
\hline 2.700 & $3.014,9+\mathrm{j} 2.690,6$ & $3.014,9+\mathrm{j} 2.690,6$ & $3.014,9+\mathrm{j} 2.690,6$ \\
\hline 3.000 & $2.918,9+\mathrm{j} 2.713,1$ & $2.918,9+\mathrm{j} 2.713,1$ & $2.918,9+\mathrm{j} 2.713,1$ \\
\hline
\end{tabular}

TABEL XII

Keluaran Daya Tiga-FASE PltB DAN GI SERTA RUgi-RUgi Total SALURAN SISTEM 33-SIMPUL

\begin{tabular}{|c|c|c|c|}
\hline $\begin{array}{c}\mathbf{P}_{\mathbf{m}} \\
(\mathbf{k W})\end{array}$ & $\begin{array}{c}\text { PLTB } \\
\text { (kW, kVAR) }\end{array}$ & $\begin{array}{c}\text { GI } \\
(\mathbf{k W , k V A R})\end{array}$ & $\begin{array}{c}\text { Rugi-Rugi } \\
(\mathbf{k W , ~ k V A R})\end{array}$ \\
\hline 300 & $273,72-\mathrm{j} 500,91$ & $11.526,9+\mathrm{j} 7.840,5$ & $655,62+\mathrm{j} 439,59$ \\
\hline 600 & $571,29-\mathrm{j} 517,35$ & $11.197,8+\mathrm{j} 7.842,0$ & $624,09+\mathrm{j} 424,65$ \\
\hline 900 & $867,51-\mathrm{j} 540,39$ & $10.874,7+\mathrm{j} 7.847,4$ & $597,21+\mathrm{j} 407,01$ \\
\hline 1.200 & $1.162,44-\mathrm{j} 569,82$ & $10.557,0+\mathrm{j} 7.862,4$ & $574,44+\mathrm{j} 392,58$ \\
\hline 1.500 & $1.456,08-\mathrm{j} 605,43$ & $10.244,4+\mathrm{j} 7.886,7$ & $555,48+\mathrm{j} 381,27$ \\
\hline 1.800 & $1.748,46-\mathrm{j} 647,10$ & $9.937,2+\mathrm{j} 7.920,0$ & $540,66+\mathrm{j} 372,90$ \\
\hline 2.100 & $2.039,64-\mathrm{j} 694,62$ & $9.634,8+\mathrm{j} 7.962,0$ & $529,44+\mathrm{j} 367,38$ \\
\hline 2.400 & $2.329,65-\mathrm{j} 747,87$ & $9.337,5+\mathrm{j} 8.012,7$ & $522,15+\mathrm{j} 364,83$ \\
\hline 2.700 & $2.618,49-\mathrm{j} 806,79$ & $9.044,7+\mathrm{j} 8.071,8$ & $518,19+\mathrm{j} 365,01$ \\
\hline 3.000 & $2.906,16-\mathrm{j} 871,26$ & $8.756,7+\mathrm{j} 8.139,3$ & $517,86+\mathrm{j} 368,04$ \\
\hline
\end{tabular}

PLTB tersebut menyerap daya reaktif dari sistem. Daya reaktif ini digunakan oleh generator induksi PLTB untuk keperluan magnetisasi rangkaian inti.

Konfirmasi lebih lanjut terhadap kevalidan metode yang diusulkan dapat ditunjukkan dengan memeriksa hasil-hasil pada Tabel XII dan Tabel XVI. Dari tabel-tabel tersebut terlihat bahwa keluaran daya GI ditambah PLTB selalu sama dengan beban sistem total ditambah rugi-rugi saluran total. Perlu dicatat bahwa rugi-rugi saluran dihitung berdasarkan impedans dan arus yang mengalir pada saluran tersebut. 
TABEL XIII

TEGANGAN TERMINAL PLTB SISTEM 25-SIMPUL

\begin{tabular}{|c|c|c|c|}
\hline $\begin{array}{c}\boldsymbol{P}_{\boldsymbol{m}} \\
(\mathbf{k W})\end{array}$ & $\begin{array}{c}\text { Fase-a } \\
(\mathbf{k V})\end{array}$ & $\begin{array}{c}\text { Fase-b } \\
(\mathbf{k V})\end{array}$ & $\begin{array}{c}\text { Fase-c } \\
(\mathbf{k V})\end{array}$ \\
\hline 300 & $3,83 \angle 0,26^{0}$ & $3,85 \angle-119,54^{0}$ & $3,89 \angle 119,90^{0}$ \\
\hline 600 & $3,87 \angle 0,74^{0}$ & $3,89 \angle-119,10^{0}$ & $3,92 \angle 120,35^{0}$ \\
\hline 900 & $3,90 \angle 1,22^{0}$ & $3,92 \angle-118,65^{0}$ & $3,94 \angle 120,80^{0}$ \\
\hline 1.200 & $3,93 \angle 1,70^{0}$ & $3,95 \angle-118,21^{0}$ & $3,97 \angle 121,25^{0}$ \\
\hline 1.500 & $3,96 \angle 2,19^{0}$ & $3,98 \angle-117,76^{0}$ & $3,99 \angle 121,70^{0}$ \\
\hline 1.800 & $3,98 \angle 2,67^{0}$ & $4,01 \angle-117,31^{0}$ & $4,01 \angle 122,16^{0}$ \\
\hline 2.100 & $4,01 \angle 3,16^{0}$ & $4,03 \angle-116,86^{0}$ & $4,03 \angle 122,61^{0}$ \\
\hline 2.400 & $4,03 \angle 3,65^{0}$ & $4,06 \angle-116,41^{0}$ & $4,05 \angle 123,07^{0}$ \\
\hline 2.700 & $4,05 \angle 4,14^{0}$ & $4,08 \angle-115,96^{0}$ & $4,07 \angle 123,53^{0}$ \\
\hline 3.000 & $4,08 \angle 4,63^{0}$ & $4,10 \angle-115,50^{0}$ & $4,09 \angle 124,00^{0}$ \\
\hline
\end{tabular}

TABEL XIV

KELUARAN DAYA PLTB SISTEM 25-SIMPUL

\begin{tabular}{|c|c|c|c|}
\hline $\begin{array}{c}\boldsymbol{P}_{\boldsymbol{m}} \\
(\mathbf{k W})\end{array}$ & $\begin{array}{c}\text { Fase-a } \\
(\mathbf{k W}, \mathbf{k V A R})\end{array}$ & $\begin{array}{c}\text { Fase-b } \\
(\mathbf{k W , ~ k V A R})\end{array}$ & $\begin{array}{c}\text { Fase-c } \\
(\mathbf{k W}, \mathbf{k V A R})\end{array}$ \\
\hline 300 & $91,10-\mathrm{j} 169,58$ & $91,02-\mathrm{j} 171,31$ & $90,86-\mathrm{j} 174,44$ \\
\hline 600 & $190,25-\mathrm{j} 176,26$ & $190,17-\mathrm{j} 178,00$ & $190,05-\mathrm{j} 180,58$ \\
\hline 900 & $288,97-\mathrm{j} 184,95$ & $288,90-\mathrm{j} 186,69$ & $288,81-\mathrm{j} 188,74$ \\
\hline 1.200 & $387,29-\mathrm{j} 195,56$ & $387,23-\mathrm{j} 197,29$ & $387,17-\mathrm{j} 198,82$ \\
\hline 1.500 & $485,21-\mathrm{j} 208,00$ & $485,17-\mathrm{j} 209,70$ & $485,14-\mathrm{j} 210,75$ \\
\hline 1.800 & $582,76-\mathrm{j} 222,19$ & $582,74-\mathrm{j} 223,86$ & $582,74-\mathrm{j} 224,46$ \\
\hline 2.100 & $679,96-\mathrm{j} 238,10$ & $679,97-\mathrm{j} 239,70$ & $679,97-\mathrm{j} 239,91$ \\
\hline 2.400 & $776,80-\mathrm{j} 255,65$ & $776,84-\mathrm{j} 257,17$ & $776,84-\mathrm{j} 257,05$ \\
\hline 2.700 & $873,30-\mathrm{j} 274,82$ & $873,39-\mathrm{j} 276,22$ & $873,36-\mathrm{j} 275,85$ \\
\hline 3.000 & $969,46-\mathrm{j} 295,57$ & $969,61-\mathrm{j} 296,82$ & $969,55-\mathrm{j} 296,28$ \\
\hline
\end{tabular}

TABEL XV

KELUARAN DAYA GI SISTEM 25-SIMPUL

\begin{tabular}{|c|c|c|c|}
\hline $\begin{array}{c}\boldsymbol{P}_{\boldsymbol{m}} \\
(\mathbf{k W})\end{array}$ & $\begin{array}{c}\text { Fase-a } \\
(\mathbf{k W}, \mathbf{k V A R})\end{array}$ & $\begin{array}{c}\text { Fase-b } \\
(\mathbf{k W}, \mathbf{k V A R})\end{array}$ & $\begin{array}{c}\text { Fase-c } \\
(\mathbf{k W}, \mathbf{k V A R})\end{array}$ \\
\hline 300 & $1.289,92+\mathrm{j} 1.221,32$ & $1.312,99+\mathrm{j} 1.224,48$ & $1.275,42+\mathrm{j} 1.222,18$ \\
\hline 600 & $1.185,24+\mathrm{j} 1.222,79$ & $1.208,19+\mathrm{j} 1.225,68$ & $1.172,66+\mathrm{j} 1.223,01$ \\
\hline 900 & $1.083,12+\mathrm{j} 1.224,38$ & $1.105,94+\mathrm{j} 1.228,78$ & $1.072,02+\mathrm{j} 1.225,75$ \\
\hline 1.200 & $983,40+\mathrm{j} 1.231,88$ & $1.006,09+\mathrm{j} 1.236,58$ & $973,41+\mathrm{j} 1.233,23$ \\
\hline 1.500 & $884,96+\mathrm{j} 1.243,09$ & $907,52+\mathrm{j} 1.247,89$ & $874,76+\mathrm{j} 1.244,29$ \\
\hline 1.800 & $790,71+\mathrm{j} 1.257,86$ & $813,13+\mathrm{j} 1.262,56$ & $781,98+\mathrm{j} 1.258,80$ \\
\hline 2.100 & $697,55+\mathrm{j} 1.276,05$ & $719,83+\mathrm{j} 1.280,44$ & $689,01+\mathrm{j} 1.276,66$ \\
\hline 2.400 & $606,41+\mathrm{j} 1.297,56$ & $628,55+\mathrm{j} 1.301,44$ & $597,81+\mathrm{j} 1.297,79$ \\
\hline 2.700 & $517,23+\mathrm{j} 1.322,28$ & $539,22+\mathrm{j} 1.325,44$ & $508,34+\mathrm{j} 1.322,10$ \\
\hline 3.000 & $429,96+\mathrm{j} 1.350,16$ & $451,80+\mathrm{j} 1.352,39$ & $420,56+\mathrm{j} 1.349,54$ \\
\hline
\end{tabular}

Hasil-hasil analisis aliran daya tersebut juga memperlihatkan bahwa dengan adanya PLTB pada sistem, salah satu keuntungan yang didapat adalah berkurangnya suplai daya dari GI sistem distribusi karena sebagian beban dapat disuplai oleh PLTB. Suplai daya dari GI ini biasanya berasal dari pembangkit-pembangkit konvensional dengan sumber energi tak-terbarukan (seperti bahan bakar fosil) yang tidak ramah lingkungan.
TABEL XVI

KelUaRAn DAYA TIGA-FASE PLTB DAN GI SERTA RUGi-RUGi TOTAL SALURAN SISTEM 25-SIMPUL

\begin{tabular}{|c|c|c|c|}
\hline $\begin{array}{c}\boldsymbol{P}_{\boldsymbol{m}} \\
(\mathbf{k W})\end{array}$ & $\begin{array}{c}\text { PLTB } \\
(\mathbf{k W}, \mathbf{k V A R})\end{array}$ & $\begin{array}{c}\text { GI } \\
(\mathbf{k W}, \mathbf{k V A R})\end{array}$ & $\begin{array}{c}\text { Rugi-Rugi } \\
(\mathbf{k W}, \mathbf{k V A R})\end{array}$ \\
\hline 300 & $272,98-\mathrm{j} 515,33$ & $3.878,33+\mathrm{j} 3.667,98$ & $231,41+\mathrm{j} 268,65$ \\
\hline 600 & $570,47-\mathrm{j} 534,84$ & $3.566,09+\mathrm{j} 3.671,48$ & $216,66+\mathrm{j} 252,64$ \\
\hline 900 & $866,68-\mathrm{j} 560,38$ & $3.261,08+\mathrm{j} 3.678,91$ & $207,86+\mathrm{j} 234,53$ \\
\hline 1.200 & $1.161,69-\mathrm{j} 591,67$ & $2.962,90+\mathrm{j} 3.701,69$ & $204,69+\mathrm{j} 226,02$ \\
\hline 1.500 & $1.455,52-\mathrm{j} 628,45$ & $2.667,24+\mathrm{j} 3.735,28$ & $202,86+\mathrm{j} 222,83$ \\
\hline 1.800 & $1.748,24-\mathrm{j} 670,51$ & $2.385,82+\mathrm{j} 3.779,22$ & $214,16+\mathrm{j} 224,71$ \\
\hline 2.100 & $2.039,90-\mathrm{j} 717,71$ & $2.106,39+\mathrm{j} 3.833,16$ & $226,39+\mathrm{j} 231,45$ \\
\hline 2.400 & $2.330,48-\mathrm{j} 769,87$ & $1.832,77+\mathrm{j} 3.896,78$ & $243,35+\mathrm{j} 242,91$ \\
\hline 2.700 & $2.620,05-\mathrm{j} 826,89$ & $1.564,79+\mathrm{j} 3.969,83$ & $264,94+\mathrm{j} 258,94$ \\
\hline 3.000 & $2.908,62-\mathrm{j} 888,67$ & $1.302,32+\mathrm{j} 4.052,08$ & $291,04+\mathrm{j} 279,41$ \\
\hline
\end{tabular}

\section{KESIMPULAN}

Metode sederhana untuk mengintegrasikan PLTB pada analisis aliran daya sistem distribusi tiga-fase telah diusulkan pada makalah ini. Metode yang diusulkan tersebut didasarkan pada model rangkaian- $\mathrm{T}$ yang sebelumnya telah berhasil diaplikasikan pada sistem distribusi tenaga listrik fase-tunggal. Pada makalah ini, model rangkaian- $T$ tersebut telah dimodifikasi dan diperluas menjadi model rangkaian- $\mathrm{T}$ tigafase. Model tersebut kemudian diikutsertakan ke dalam analisis aliran daya dari jaringan distribusi tak-seimbang. Metode yang diusulkan ini juga telah divalidasi dengan menggunakan dua sistem distribusi representatif, yaitu sistem 33-simpul dan 25-simpul. Hasil-hasil penyelidikan yang dilakukan pada sistem tersebut memperlihatkan bahwa metode yang diusulkan valid dan akurat.

\section{REFERENSI}

[1] J.H. Teng, "Modelling Distributed Generations in Three-Phase Distribution Load Flow," IET Gener. Transm. Distrib., Vol. 2, No. 3, hal. 330-340, 2008.

[2] M.H. Haque, "Evaluation of Power Flow Solutions with Fixed Speed Wind Turbine Generating Systems," Energy Conversion and Management, Vol. 79, hal. 511-518, 2014.

[3] J. Wang, C. Huang, dan A.F. Zobaa, "Multiple-Node Models of Asynchronous Wind Turbines in Wind Farms for Load Flow Analysis," Electric Power Components and Systems, Vol. 44, No. 2, hal. 135-141, 2015.

[4] M.H. Haque, "Incorporation of Fixed Speed Wind Turbine Generators in Load Flow Analysis of Distribution Systems," International Journal of Renewable Energy Technology, Vol. 6, No. 4, hal. 317-324, 2015.

[5] A. Feijoo, J.L. Pazos, dan D. Villanueva, "Conventional Asynchronous Wind Turbine Models - Mathematical Expressions for the Load Flow Analysis," International Journal of Energy Engineering (IJEE), Vol. 44, No. 6, hal. 269-278, 2013.

[6] A. Feijoo dan D. Villanueva, "A PQ Model for Asynchronous Machines Based on Rotor Voltage Calculation," IEEE Trans. Energy Conversion, Vol. 31, No. 2, hal. 813-814, 2016.

[7] A. Feijoo dan D. Villanueva, "Correction to 'A PQ Model for Asynchronous Machines Based on Rotor Voltage Calculation'," IEEE Trans. Energy Conversion, Vol. 31, No. 3, hal. 1228-1228, 2016.

[8] R. Gianto, K.H. Khwee, H. Priyatman, dan M. Rajagukguk, "Two-Por Network Model of Fixed-Speed Wind Turbine Generator for Distribution System Load Flow Analysis," TELKOMNIKA, Vol. 17, No. 3, hal. 1569-1575, 2019. 
[9] R. Gianto, "T-Circuit Model of Asynchronous Wind Turbine for Distribution System Load Flow Analysis," International Energy Journal, Vol. 19, No. 2, hal. 77-88, 2019.

[10] R. Gianto, "Pemodelan Pembangkit Listrik Tenaga Angin Kecepatan Tetap untuk Analisis Aliran Daya," Jurnal Nasional Teknik Elektro (JNTE), Vol. 8, No. 1, hal. 8-15, 2019.

[11] R. Gianto, "Integrasi Model Pembangkit Listrik Tenaga Angin pada Analisis Aliran Daya Sistem Tenaga," Jurnal Rekayasa Elektrika, Vol. 16, No. 3, hal. 161-167, 2020.

[12] R. Gianto dan K.H. Khwee, "A New Method for Load Flow Solution of Electric Power Distribution System," International Review of Electrical Engineering, Vol. 11, No. 5, hal. 535-541, 2016.
[13] E.R. Ramos, A.G. Exposito, dan G.A. Cordero, "Quasi-Coupled ThreePhase Radial Load Flow," IEEE Trans. Power Systems, Vol. 19, No. 2 , hal. 776-781, 2004.

[14] V. Ganesh, S. Sivanagaraju, dan T. Ramana, "Feeder Reconfiguration for Loss Reduction in Unbalanced Distribution System Using Genetic Algorithm," International Journal of Computer, Electrical, Automation, Control and Information Engineering, Vol. 3, No. 4, hal. 1050-1058, 2009. 